International Journal of Biology, Pharmaey and Allied Sciences (IJBPAS)

'A Bridge Bestuen caboratory and QRender'

WwW.iibpas.com

\title{
EFFECT OF HYDROPHILIC AND HYDROPHOBIC POLYMER ON THE RELEASE RATE OF METOCLOPRAMIDE FROM SUSTAINED- RELEASE TABLET
}

\author{
AYESHA MAHMOOD ${ }^{1}$, SAJID ALI ${ }^{1,2}$, UZAIR NAGRA ${ }^{1},{ }^{*}$ MARYAM SHABBIR ${ }^{1}$, \\ AZEEMA TAYYAB ${ }^{1}$ \\ ${ }^{1}$ Faculty of Pharmacy, University of Lahore, Lahore, Pakistan \\ ${ }^{2}$ Department of Pharmaceutical Technology and Biopharmaceutics, Philipps University, Marburg,
}

Germany

*Corresponding author: Maryam Shabbir, maryam.shabbir@live.com

Received $15^{\text {th }}$ Feb. 2018; Revised $14^{\text {th }}$ March. 2018; Accepted $10^{\text {th }}$ April 2018; Available online $1^{\text {st }}$ July 2018

DOI: https://doi.org/10.31032/IJBPAS/2018/7.7.4471

\begin{abstract}
Metoclopramide (MCP) is a dopamine $\mathrm{D}_{2}$ receptor antagonist, used as antiemetic to treat gastrointestinal disorders. Dosing frequencies of MCP are high due to shorter duration of action $(5 \pm 1 \mathrm{~h})$. Frequent administrations results in plasma drug level fluctuations which contribute toward extra pyramidal effects and hence less patient compliance. To avoid such effects, sustained release formulation may be developed to achieve drug release at a predetermined rate to obtain desired plasma drug profile. The purpose of the study was to form matrix tablets of MCP and to evaluate the relationship of different concentrations of HPMC and EC in order to achieve zero order release. For preparing matrix tablets MCP and various percentages of HPMC and EC polymers were blended and formulated into matrix tablets by direct compression. Formulations were evaluated for physical parameters and in vitro dissolution properties over a period of 12 hours. Drug release kinetics was analyzed by applying a number of release kinetic models. Release kinetics of MCP from matrices was principally regulated by HPMC and EC. Increased concentrations of EC delayed drug release. F1, F2 corresponded best to Hixon-crowell
\end{abstract}


and gave $100 \%$ release for 12 hours while F10 and F13 corresponded best to zero order kinetics and gave $100 \%$ release for 12 hours by super case II transport mechanism. The sustained release matrix tablets of MCP, with less concentration fluctuations, are a good alternate compared to conventional oral dosage forms.

Keywords: Metoclopramide, HPMC, EC, matrix tablet, sustain release, kinetics 


\section{INTRODUCTION}

Metoclopramide hydrochloride (MCP) is a dopamine $D_{2}$ receptor antagonist, used to treat gastrointestinal disorders such as nausea and vomiting by acting on the lower esophageal sphincter [1, 2]. The shorter biological half-life $(5 \mathrm{~h})$ and rapid gastrointestinal absorption demands frequent dosing. With frequent dosing, the plasma drug concentrations fluctuate and cause extra pyramidal side effects [1, 3]. To avoid undesired effects and frequent administrations to improve patient compliance, a formulation which can control the drug release rate may be developed. MCP being a BCS class III drug (high water solubility and low permeability) may be a good candidate for developing an oral controlled drug release system.

Matrix system is an earliest oral extended release system for medicinal use which provides continuous drug release. Matrix tablets are most commonly used dosage form which optimizes the plasma drug levels by controlling the drug release from the formulation into gastrointestinal track. Matrix tablets are reliably useful, especially for high potency drugs, as they offer high safety margin, increased patient compliance by reducing side effects and doses. Hydrophilic matrix system are widely developed as they are cost effective and easily prepared with desired release profiles [4]. The hydrophilic polymer, such as Hydroxypropyl methylcellulose (HPMC), in contact with aqueous medium swells and forms gel on the surface of the system. Then drug releases by dissolution, diffusion and/or erosion phenomena [5, 6]. Hydrophilic matrix containing hydrophilic polymer alone is not suitable for highly soluble drugs to provide extended release so a hydrophobic polymer may be added to achieve desired drug release rates. HPMC is used as a first choice in hydrophilic matrix as it is stable over a wide $\mathrm{pH}$ range (3-11), nontoxic, inert and provide a robust mechanism for controlled release [7]. Hydrophobic matrix containing hydrophobic polymer, Ethyl cellulose (EC) alone, is also not suitable for sustain drug delivery as it slows the drug release below optimum level and high cost is required for development [8]. A matrix system adding a hydrophobic polymer along with hydrophilic polymer may best be employed to achieve desired release profiles [9]. The present study was undertaken to develop matrix tablets of MCP by using different ratios of hydrophilic swellable polymer; HPMC and a hydrophobic, almost non swellable polymer; EC. The 
formulations developed with different concentrations of two polymers were then evaluated for physical properties and dissolution profile by employing various release kinetic models.

\section{MATERIALS AND METHOD}

\section{Materials}

Metoclopramide hydrochloride (generously donated by Medi Search Pharma Pvt. Ltd.), Hydroxypropyl methylcellulose K4M(Merck, Germany), Ethyl cellulose (Merck, Germany), Avicel pH 102 (UniChem),Polyvinyl pyrollidone (Merck, Germany), magnesium stearate (Uni-Chem), Talc (Uni-Chem), Hydrochloric acid (BDH, England) and potassium dihydrogen phosphate (Fluka, Germany).

\section{Preparation of tablets}

Table 1: Formulation of MCP sustained release tablets using HPMC and EC as rate controlling polymers

\begin{tabular}{|c|c|c|c|c|c|c|c|c|c|c|c|c|c|c|}
\hline \multirow{2}{*}{ Code } & \multirow{2}{*}{$\begin{array}{c}\text { Drug } \\
\text { mg }\end{array}$} & \multicolumn{2}{|c|}{ HРМС } & \multicolumn{2}{|c|}{ EC } & \multicolumn{2}{|c|}{ PVP } & \multicolumn{2}{|c|}{ Avicel 102} & \multicolumn{2}{|c|}{$\begin{array}{c}\text { Mg. } \\
\text { Stearate }\end{array}$} & \multicolumn{2}{|c|}{ Talc } & \multirow{2}{*}{$\begin{array}{c}\text { Weight } \\
\text { mg }\end{array}$} \\
\hline & & $\%$ & mg & $\%$ & mg & $\%$ & mg & $\%$ & mg & $\%$ & mg & $\%$ & mg & \\
\hline F1 & 100 & 5 & 10 & - & - & 5 & 10 & 37 & 74 & 2 & 4 & 1 & 2 & 200 \\
\hline F2 & 100 & 10 & 20 & - & - & 5 & 10 & 32 & 64 & 2 & 4 & 1 & 2 & 200 \\
\hline F3 & 100 & 15 & 30 & - & - & 5 & 10 & 27 & 54 & 2 & 4 & 1 & 2 & 200 \\
\hline F4 & 100 & 20 & 40 & - & - & 5 & 10 & 22 & 44 & 2 & 4 & 1 & 2 & 200 \\
\hline F5 & 100 & 25 & 50 & - & - & 5 & 10 & 17 & 34 & 2 & 4 & 1 & 2 & 200 \\
\hline F6 & 100 & - & - & 5 & 10 & 5 & 10 & 37 & 74 & 2 & 4 & 1 & 2 & 200 \\
\hline F7 & 100 & - & - & 10 & 20 & 5 & 10 & 32 & 64 & 2 & 4 & 1 & 2 & 200 \\
\hline F8 & 100 & - & - & 15 & 30 & 5 & 10 & 27 & 54 & 2 & 4 & 1 & 2 & 200 \\
\hline F9 & 100 & - & - & 20 & 40 & 5 & 10 & 22 & 44 & 2 & 4 & 1 & 2 & 200 \\
\hline F10 & 100 & - & - & 25 & 50 & 5 & 10 & 17 & 34 & 2 & 4 & 1 & 2 & 200 \\
\hline F11 & 100 & 5 & 10 & 20 & 40 & 5 & 10 & 17 & 34 & 2 & 4 & 1 & 2 & 200 \\
\hline F12 & 100 & 10 & 20 & 15 & 30 & 5 & 10 & 17 & 34 & 2 & 4 & 1 & 2 & 200 \\
\hline F13 & 100 & 15 & 30 & 10 & 20 & 5 & 10 & 17 & 34 & 2 & 4 & 1 & 2 & 200 \\
\hline F14 & 100 & 20 & 40 & 5 & 10 & 5 & 10 & 17 & 34 & 2 & 4 & 1 & 2 & 200 \\
\hline
\end{tabular}




\section{Characterization of granules}

Prior to compression, the granules were evaluated for their flow properties. Angle of repose was determined by the funnel method, whereas bulk density and tapped density were evaluated by cylinder method. Carr's index and angle of repose were calculated respectively by the formulas given below.

Carr's Index $=($ Tapped density - Bulk density) / (Tapped density) * 100

Angle of repose $=\tan \Theta=($ Height $) /($ Radius $)$

\section{Characterization of tablets}

The properties of compressed tablets, such as hardness, friability, weight variation and content uniformity were determined. Hardness by Monsanto hardness tester $(n=10)$ was determined. Friability was determined by friabilator (Curio, Pakistan). Weight variation testing was carried out as per USP stated procedure $(n=20)$.

For content uniformity, 10 tablets were crushed and powder equivalent to $200 \mathrm{mg}$ was taken. The powder was dissolved in phosphate buffer $\mathrm{pH} 6.8$ on magnetic stirrer. A sample of $5 \mathrm{ml}$ was taken, filtered, appropriately diluted and analyzed spectrophotometrically for absorbance at 309 $\mathrm{nm}$.

\section{In vitro dissolution studies}

The effect of simulated gastric fluid (SGF) and simulated intestinal fluid (SIF) on the release characteristics of selected formulation was determined. The release profile was evaluated in a medium of SGF for 2 hours in dissolution apparatus containing $750 \mathrm{ml}$ of $\mathrm{pH}$ 1.2. Then, $250 \mathrm{ml}$ of $0.2 \mathrm{M}$ potassium dihydrogen phosphate $\left(\mathrm{KH}_{2} \mathrm{PO}_{4} \cdot 12 \mathrm{H}_{2} \mathrm{O}\right)$ was added in the dissolution basket to raise $\mathrm{pH}$ of the medium to 6.8 and total dissolution volume to $1000 \mathrm{ml}$. A sample of $5 \mathrm{ml}$ was withdrawn after a suitable time interval over a period of 12 hours. The sample was filtered and analyzed spectrophotometrically at 309 $\mathrm{nm}$.

\section{Data analysis}

The percentage drug release from the matrix tablets was fitted to zero order, first order, Higuchi equation and Hixson-Crowell model. As these models do not explain drug release mechanism due to swelling (upon hydration) thereby the dissolution data was also fitted into Korsmeyer Peppas equation[10]. According to exponential equation, a value of $\mathrm{n}<0.5$ indicates Fickian diffusion, $0.5<\mathrm{n}<1.0$ non-Fickian (anomalous) release, $\mathrm{n}=1.0$ zero order release, while $\mathrm{n}>1.0$ indicates super case II (erosion) transport [11].

\section{RESULT AND DISCUSSION}

\section{Flow properties of granules}

Before compression, the formed granules were evaluated for their flow properties. Angle of repose andCarr's index (\%) were 
evaluated as given in Table 2. The formulations from F1 to F10 showed good flowability as shown by $<40^{\circ}$ angle of repose and percentage compressibility as shown by $<20$ [12]. The granules developed for F10 to F14 showed excellent flowability as shown by angle of repose $<30^{\circ}$. This indicated that HPMC and EC both contributed towards improved flow properties.

\section{Tablets characteristics}

\section{Hardness, thickness and content uniformity}

The compressed tablets were evaluated for hardness and ranged between 9.40 to $10.9 \mathrm{~N}$ (Table 3). The results showed that prepared tablets can withstand the stress and pressure during handling, packaging and transportation. The weight of tablets were within 198.3 to $205.5 \mathrm{mg}$ which complied with the official limits of USP for $200 \mathrm{mg}$ tablet, i.e. an allowed percentage deviation of $\pm 7.5 \%$.

The friability of all formulations was less than $1 \%$ conforming to the official compendia. This indicates that formulations showed good strength against shock or mechanical abrasion. The drug content was determined analytically for absorbance at $309 \mathrm{~nm}$. The content levels for all the formulations ranged from $97.48 \%$ to $99.78 \%$ which conform to the official limits stated in USP, i.e. $\pm 15 \%$ [13].

\section{In vitro dissolution}

HPMC is most commonly used hydrophilic polymer for designing matrix drug delivery systems. It is mixed alkyl hydroxyalkyl cellulose ether containing methoxyl and hydroxypropyl groups. The degree of hydration depends on the nature of these substituent present in HPMC. Specifically, the rate of hydration increases with increase in the hydroxypropyl content. In the present study, HPMC K4M was used as a hydrophilic matrix agent because of its ability to form a viscous gel on contact with aqueous medium. Formulations were developed by increasing HPMC concentration from F1-F5. With an increase in HPMC from $5 \%$ to $25 \%$ concentrations, faster release was achieved. $\mathrm{t}_{75 \%}$ was achieved in 8.6 hours for formulation F1 and F5 released the same amount of drug in just 7.3 hours as given in Table 4. Faster release of drug from matrix was probably due to the rapid hydration of polymer resulting in faster dissolution of the highly soluble drug. Hydrophilic polymer HPMC is considered for most formulations as it gives an initial burst release by forming a viscous gel immediately [14]. The percentage drug release with respect to time for formulation 
F1-F5 is shown in Figure 1.A binder such as PVP (K 30) may be added in hydrophilic matrix to retard release of water soluble drug [15]. As the solubility of HPMC is $\mathrm{pH}$ independent, therefore increase folds of drug release was seen in both SGF and SIF $(\mathrm{pH}$ 1.2 and $\mathrm{pH} 6.8$ respectively) as indicated by $29.0 \%$ drug release for $\mathrm{F} 1$ to $37.68 \%$ for $\mathrm{F}-5$ after 2 hours[16].

Formulations F6 to F10 were developed by adding $\mathrm{EC}$ in concentrations in range from $5 \%-25 \%$. With increasing proportions of EC there was an evident increase of drug dissolved percentage in SIF and decrease in burst effect in SGF as less than $10 \%$ of the drug released from $\mathrm{F} 6$ to $\mathrm{F} 10$ at increased $\mathrm{EC}$ concentrations. $\mathrm{t}_{75 \%}$ release was achieved after 7.6 hours in F-6 having 5\% EC while with $25 \% \mathrm{EC}$, the same percentage release was delayed to 8.7 hours. Increased diffusional path length of EC formed matrix with less porosity reduces water penetration through the micropores resulting in slower drug release [17]. The release of drug in acidic medium at $\mathrm{pH} 1.2$ indicated a much lower release rate with an increase in EC concentration. Thus, EC can retard the drug release in lower $\mathrm{pH}$, possibly due to polymer hydrophobicity and its solubility in alkali solution[18]. The percentage drug release of formulations with increasing EC concentration with respect to time is shown in Figure 2.

The formulations F11 to F14, having both HPMC and EC, showed $t_{75 \%}$ in a range of 7.6 to 10.75 hours after administration. The formulation F11 and F12 showed sustained release but even after 12 hours 100\% drug release was not achieved. Formulation F13 showed sustained and $100 \%$ release in 12 hours. The rate of drug release in SGF was less than $5 \%$ in acidic medium. This is attributed to the decreased penetration of the solvent molecules into the hydrophobic polymer which leads to decreased diffusion of drug from the matrix system [19]. The percentage drug release of F11-F14 with respect to time is shown in Figure 3.

The formulations $\mathrm{F} 1$ and F2 followed Hixson-Crowell model which signifies dissolution from the planes was parallel to the surface. The formulations F3, F4 and F5 followed Higuchi model as best fit; indicating diffusion as release kinetics. F6 to F14 followed zero order kinetics i.e. drug release was independent of the drug concentration. To study the drug release behavior, Korsmeyer-Peppas model was applied. F1 to F6 and F14 showed nonfickian release explaining both diffusion and erosion as the main release mechanism indicated by values in a range 0.45-0.89. 
Formulations F7 to F13 revealed super case erosion of polymer as drug release behavior

II transport mechanism which signifies $[11,20,21]$.

Table 2: Flow properties of MCP granules prepared for direct compression

\begin{tabular}{|c|c|c|c|c|}
\hline Code & Carr's index (\%) & Flow property & Angle of repose & Flow property \\
\hline F1 & 13.39 & Good & $31.85^{\circ}$ & Good \\
\hline F2 & 17.12 & Fair & $33.14^{\circ}$ & Good \\
\hline F3 & 18.02 & Fair & $33.27^{\circ}$ & Fair \\
\hline F4 & 16.33 & Fair & $36.17^{\circ}$ & Fair \\
\hline F5 & 17.30 & Fair & $32.45^{\circ}$ & Good \\
\hline F6 & 15.00 & Good & $\mathbf{3 3 . 0 0}^{\circ}$ & Excellent \\
\hline F7 & 9.09 & Excellent & $\mathbf{2 8 . 4 5}^{\circ}$ & Good \\
\hline F8 & 12.50 & Good & $29.53^{\circ}$ & Excellent \\
\hline F9 & 12.00 & Excellent & $25.50^{\circ}$ & Excellent \\
\hline F10 & 5.88 & Excellent & $29.25^{\circ}$ & Excellent \\
\hline F11 & 4.76 & Good & $25.80^{\circ}$ & Excellent \\
\hline F12 & 15.00 & Excellent & $29.63^{\circ}$ & Excellent \\
\hline F13 & 9.80 & Good & & \\
\hline F14 & 12.50 & & & \\
\hline
\end{tabular}

Table 3: Physical and chemical evaluation of sustained release tablets of MCP $( \pm$ S.D.)

\begin{tabular}{|c|c|c|c|c|c|}
\hline Code & $\begin{array}{c}\text { Hardness } \\
(\mathrm{kg})\end{array}$ & $\begin{array}{c}\text { Thickness } \\
(\mathrm{mm})\end{array}$ & $\begin{array}{c}\text { Weight } \\
(\mathrm{mg})\end{array}$ & $\begin{array}{c}\text { Friability } \\
(\%)\end{array}$ & Content uniformity (mg) \\
\hline F1 & $10.3 \pm 0.5$ & $3.55 \pm 0.15$ & $203.2 \pm 1.5$ & 0.15 & $99.78 \pm 1.2$ \\
\hline F2 & $9.6 \pm 0.3$ & $3.50 \pm 0.23$ & $201.6 \pm 0.5$ & 0.52 & $97.57 \pm 0.8$ \\
\hline F3 & $9.8 \pm 0.3$ & $3.60 \pm 0.10$ & $202.2 \pm 1.0$ & 0.41 & $98.43 \pm 0.2$ \\
\hline F4 & $9.7 \pm 0.6$ & $3.75 \pm 0.36$ & $198.3 \pm 1.0$ & 0.24 & $99.21 \pm 0.7$ \\
\hline F5 & $9.5 \pm 0.1$ & $3.75 \pm 0.15$ & $205.4 \pm 2.5$ & 0.61 & $98.84 \pm 0.4$ \\
\hline F6 & $10.4 \pm 0.6$ & $3.50 \pm 0.63$ & $200.2 \pm 0.0$ & 0.49 & $99.48 \pm 1.1$ \\
\hline F7 & $10.9 \pm 0.4$ & $3.65 \pm 0.42$ & $201.3 \pm 0.5$ & 0.15 & $99.15 \pm 0.5$ \\
\hline F8 & $9.8 \pm 0.6$ & $3.70 \pm 0.21$ & $203.0 \pm 1.5$ & 0.28 & $98.27 \pm 0.4$ \\
\hline F9 & $9.9 \pm 0.2$ & $3.40 \pm 0.16$ & $199.4 \pm 0.5$ & 0.40 & $99.73 \pm 0.1$ \\
\hline F10 & $10.0 \pm 0.4$ & $3.55 \pm 0.42$ & $202.6 \pm 1.0$ & 0.24 & $98.79 \pm 0.6$ \\
\hline F11 & $10.5 \pm 0.1$ & $3.45 \pm 0.26$ & $199.2 \pm 0.5$ & 0.37 & $97.48 \pm 1.0$ \\
\hline F12 & $10.6 \pm 0.6$ & $3.45 \pm 0.10$ & $200.6 \pm 0.0$ & 0.45 & $98.92 \pm 0.7$ \\
\hline F13 & $9.70 \pm 0.2$ & $3.35 \pm 0.42$ & $202.4 \pm 1.0$ & 0.49 & $99.67 \pm 0.5$ \\
\hline F14 & $9.40 \pm 0.4$ & $3.70 \pm 0.27$ & $205.5 \pm 2.5$ & 0.20 & $99.15 \pm 0.8$ \\
\hline
\end{tabular}

Table 4: Drug release profile of sustained release tablet of MCP
Code
$\mathbf{t}_{\mathbf{2 5} \%}$
$\mathbf{t}_{\mathbf{5 0} \%}$ $\mathbf{t}_{\mathbf{7 5} \%}$
$\mathbf{t}_{\mathbf{8 0} \%}$ $\mathbf{t}_{\mathbf{9 0} \%}$ 


\begin{tabular}{|l|l|l|l|l|l|}
\hline \hline F1 & 2.87 & 5.74 & 8.61 & 9.18 & 10.33 \\
\hline F2 & 2.74 & 5.48 & 8.22 & 8.77 & 9.86 \\
\hline F3 & 2.65 & 5.30 & 7.95 & 8.48 & 9.54 \\
\hline F4 & 2.62 & 5.24 & 7.87 & 8.39 & 9.44 \\
\hline F5 & 2.43 & 4.87 & 7.30 & 7.79 & 8.76 \\
\hline F6 & 2.56 & 5.11 & 7.67 & 8.18 & 9.20 \\
\hline F8 & 2.69 & 5.37 & 8.06 & 8.60 & 9.67 \\
\hline F9 & 2.75 & 5.51 & 8.26 & 8.81 & 9.91 \\
\hline F10 & 2.77 & 5.54 & 8.31 & 8.87 & 9.98 \\
\hline F11 & 2.91 & 5.82 & 8.72 & 9.30 & 10.47 \\
\hline F12 & 3.59 & 7.17 & 10.76 & 11.47 & 12.91 \\
\hline F13 & 3.23 & 6.46 & 9.69 & 10.33 & 11.62 \\
\hline F14 & 2.57 & 6.13 & 9.19 & 9.81 & 11.03 \\
\hline
\end{tabular}

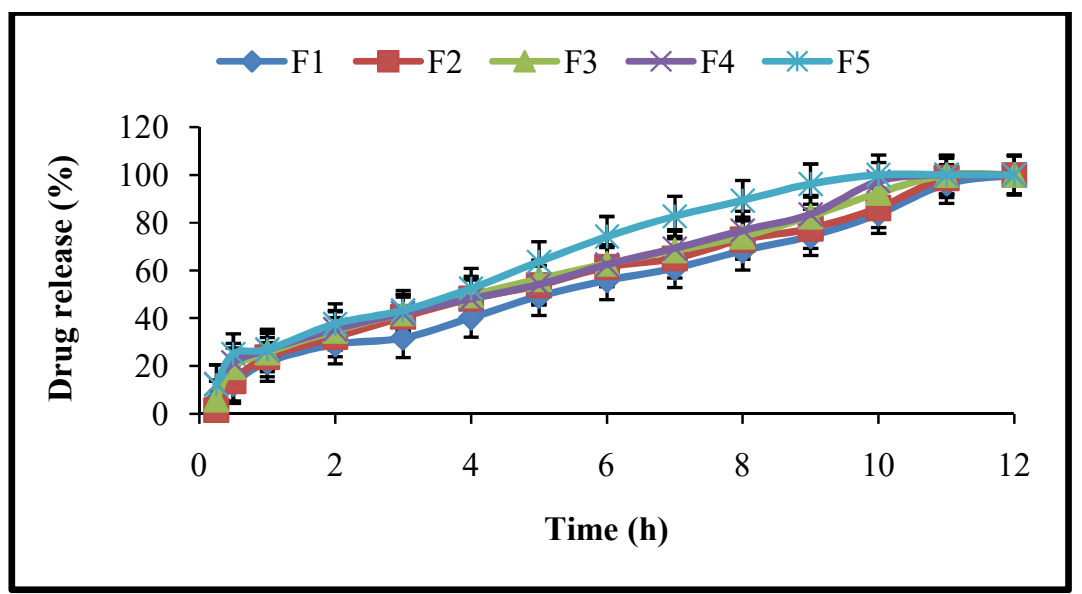

Figure 1: In vitro dissolution profile of formulation containing HPMC as release retardant

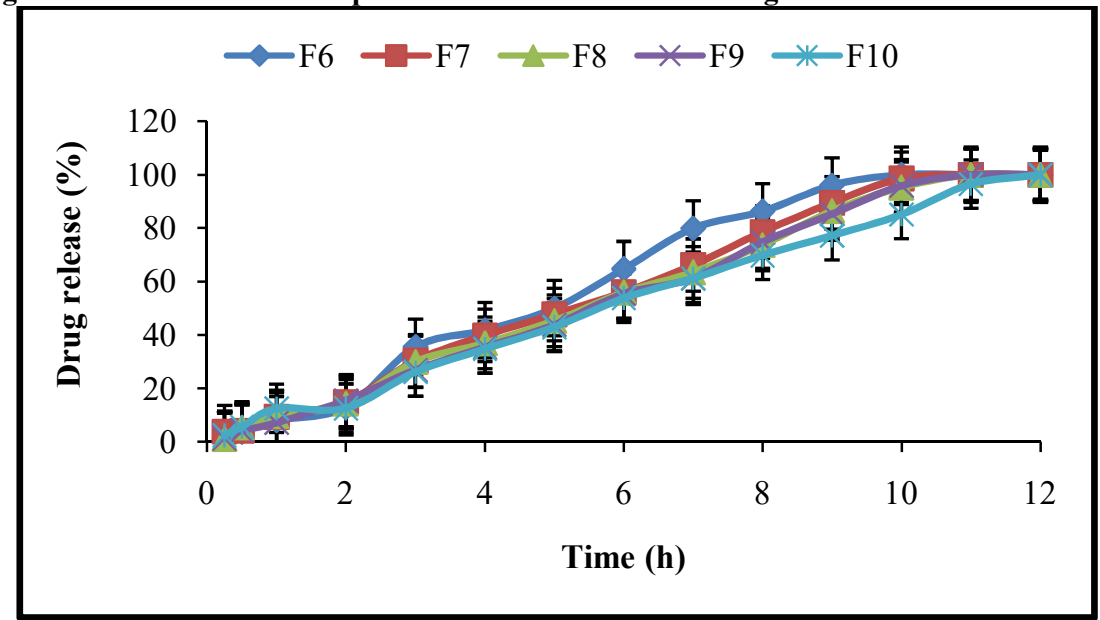

Figure 2: In vitro dissolution profile of formulation containing EC as release retardant 


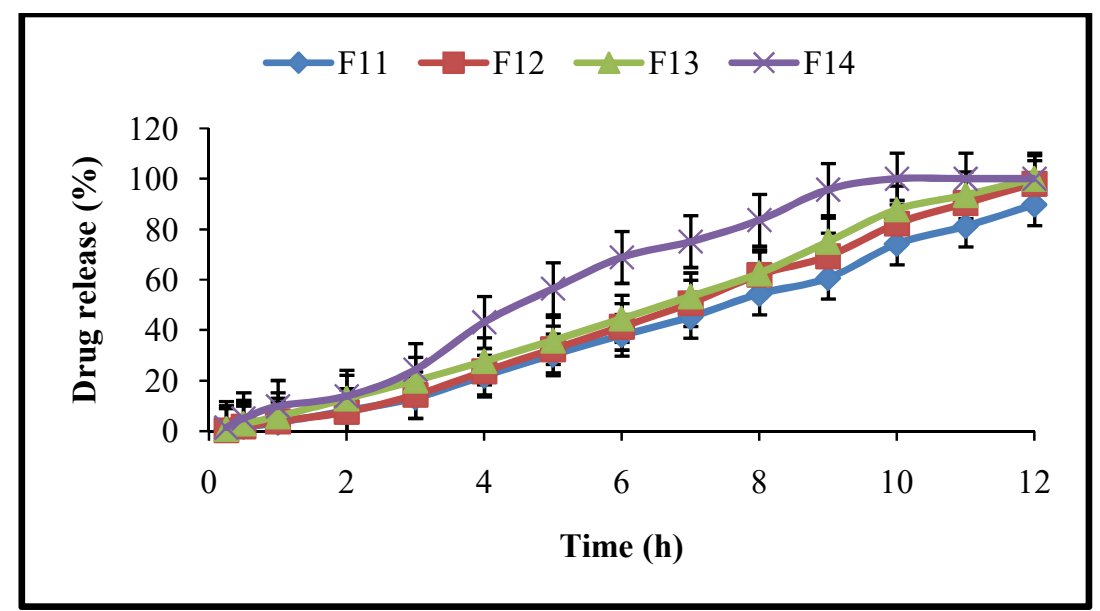

Figure 3: In vitro dissolution profile of formulation containing EC as release retardant

Table 5: Kinetic models of sustained release tablets of MCP

\begin{tabular}{|c|c|c|c|c|c|c|}
\hline Code & $\begin{array}{c}\text { Zero Order } \\
\left(\mathbf{R}^{2}\right)\end{array}$ & $\begin{array}{c}\text { First Order } \\
\left(\mathbf{R}^{2}\right)\end{array}$ & $\begin{array}{c}\text { Higuchi } \\
\left(\mathbf{R}^{2}\right)\end{array}$ & $\begin{array}{c}\mathbf{K P} \\
\left(\mathbf{R}^{2}\right) \\
\end{array}$ & n & $\begin{array}{c}\text { Hixson Crowel } \\
\left(\mathbf{R}^{2}\right) \\
\end{array}$ \\
\hline F1 & 0.9544 & 0.9407 & 0.9294 & 0.9850 & 0.754 & 0.9596 \\
\hline F2 & 0.9130 & 0.9581 & 0.9581 & 0.9873 & 0.663 & 0.9663 \\
\hline F3 & 0.8800 & 0.9485 & 0.9709 & 0.9879 & 0.618 & 0.9555 \\
\hline F4 & 0.8640 & 0.9257 & 0.9656 & 0.9790 & 0.607 & 0.9364 \\
\hline F5 & 0.7992 & 0.9455 & 0.9760 & $\mathbf{0 . 9 7 9 6}$ & $\mathbf{0 . 5 5 7}$ & $\mathbf{0 . 9 5 8 0}$ \\
\hline F6 & 0.9613 & 0.9185 & 0.8727 & 0.9677 & 0.863 & 0.9547 \\
\hline F7 & 0.9855 & 0.9186 & 0.8699 & 0.9867 & 0.926 & 0.9545 \\
\hline F8 & 0.9912 & 0.9191 & 0.8649 & 0.9913 & 0.956 & 0.9541 \\
\hline F9 & 0.9918 & 0.9113 & 0.8519 & 0.9911 & 0.995 & 0.9476 \\
\hline F10 & 0.9960 & 0.9262 & 0.8640 & 0.9959 & 0.976 & 0.9583 \\
\hline F11 & 0.9771 & 0.8932 & 0.7720 & 0.9984 & 1.297 & 0.9230 \\
\hline F12 & 0.9757 & $\mathbf{0 . 8 7 3 7}$ & 0.7688 & 0.9977 & 1.301 & 0.9092 \\
\hline F13 & 0.9878 & 0.8879 & 0.8024 & 0.9972 & 1.187 & 0.9239 \\
\hline F14 & 0.9622 & 0.9173 & 0.8705 & 0.9678 & 0.869 & 0.9540 \\
\hline
\end{tabular}

\section{CONCLUSION}

Matrix tablets of MCP were prepared by adding different percentages of HPMC and EC. Direct compression method was adopted for preparation of matrix tablets. The comparative studies of all formulations revealed that MCP release was affected by the proportions of added polymers. The formulations complied with requirement of friability, hardness, drug content and weight variation given in official compendia. The release kinetics showed diffusion, erosion and a surface dissolution as the release mechanisms. Formulation F13 corresponded to satisfactory sustained release upto 12 hours. The initial gastric release $(\mathrm{pH} 1.2)$ due to HPMC was also reasonable with zero order, super case II drug release mechanism. 
Therefore, by adding HPMC and EC, MCP matrix tablets can be well formulated for sustained drug delivery.

\section{Conflict of interest}

The authors declare no conflict of interest.

\section{REFERENCE}

[1] Abdel-Rahman SI, Mahrous GM, ElBadry M. Preparation and comparative evaluation of sustained release metoclopramide hydrochloride matrix tablets. Saudi Pharmaceutical Journal. 2009; 17 (4): 283-288.

[2] Cohen S, Dimarino AJ. Mechanism of action of metoclopramide on opossum lower esophageal sphincter muscle. Gastroenterology. 1976; 71 (6): 996-998.

[3] Stosik A, Junginger H, Kopp S, Midha K, Shah V, Stavchansky S, et al. Biowaiver monographs for immediate release solid oral dosage forms: Metoclopramide hydrochloride. Journal of pharmaceutical sciences. 2008; 97 (9): 3700-3708.

[4] Nokhodchi A, Raja S, Patel P, AsareAddo K. The role of oral controlled release matrix tablets in drug delivery systems. BioImpacts: BI. 2012; 2 (4): 175.
[5] Tiwari SB, Rajabi-Siahboomi AR. Extended-release oral drug delivery technologies: monolithic matrix systems. Drug delivery systems. 2008; 217-243.

[6] Siepmann J, Peppas N. Mathematical modeling of controlled drug delivery. Advanced drug delivery reviews. 2001; 48 (2-3): 137-138.

[7] Lee H, Chan L, Heng P. Influence of partially cross-linked alginate used in the production of alginate microspheres by emulsification. Journal of microencapsulation. 2005; 22 (3): 275-280.

[8] Ahmed S, Ashraf M, Mohsin S. Ethyl cellulose-based solid matrix system for sustaining release of naproxen. Pakistan journal of biological sciences. 2007; 10 (4): 668-672.

[9] Nish S, Mathew G, Lincy J. Matrix Tablets: An effective way for oral controlled release drug delivery. Iranian Journal of Pharmaceutical Sciences. 2012; 8 (3): 165-170.

[10] Kuksal A, Tiwary AK, Jain NK, Jain S. Formulation and in vitro, in vivo evaluation of extended-release matrix tablet of zidovudine: influence of combination of hydrophilic and hydrophobic matrix 
formers. aaps Pharmscitech. 2006; 7

(1): E1-E9.

[11] Siepmann J, Peppas NA. Modeling of drug release from delivery systems based on hydroxypropryl methylcellulose (HPMC). Adv Drug Deliver Rev. 2001; (48): 139-157.

[12] Raut NS, Somvanshi S, Jumde AB, Khandelwal HM, Umekar MJ, Kotagale NR. Ethyl cellulose and hydroxypropyl methyl cellulose buoyant microspheres of metoprolol succinate: Influence of $\mathrm{pH}$ modifiers. International journal of pharmaceutical investigation. 2013; 3 (3): 163.

[13] KATORI N, A proposal for revision of the content uniformity test and weight variation test, in: JP Forum, 1995, pp. 81-92.

[14] Reza MS, Quadir MA, Haider SS. Comparative evaluation of plastic, hydrophobic and hydrophilic polymers as matrices for controlledrelease drug delivery. J Pharm Pharm Sci. 2003; 6 (2): 282-291.

[15] Bose A, Wong TW, Singh N. Formulation development and optimization of sustained release matrix tablet of Itopride $\mathrm{HCl}$ by response surface methodology and its evaluation of release kinetics. Saudi Pharmaceutical Journal. 2013; 21 (2): 201-213.

[16] Conti S, Maggi L, Segale L, Machiste EO, Conte U, Grenier P, et al. Matrices containing $\mathrm{NaCMC}$ and HPMC: 2. Swelling and release mechanism study. International Journal of Pharmaceutics. 2007; 333 (1): 143-151.

[17] Chandran S, Asghar LF, Mantha N. Design and evaluation of ethyl cellulose based matrix tablets of ibuprofen with $\mathrm{pH}$ modulated release kinetics. Indian journal of pharmaceutical sciences. 2008; 70 (5): 596.

[18] Prasertmanakit S, Praphairaksit N, Chiangthong W, Muangsin N. Ethyl cellulose microcapsules for protecting and controlled release of folic acid. aaps Pharmscitech. 2009; 10 (4): 1104-1112.

[19] Tiwari SB, Murthy TK, Pai MR, Mehta PR, Chowdary PB. Controlled release formulation of tramadol hydrochloride using hydrophilic and hydrophobic matrix system. aaps Pharmscitech. 2003; 4 (3): 18-23. 
[20] Zohra R, Malana MA. Development of Gastroretentive Drug Delivery Systems Based on N-Isopropylacrylamide Hydrogels. EC Gastroenterology and Digestive System. 2018; 5 78-96.

[21] Dash S, Murthy PN, Nath L, Chowdhury P. Kinetic modeling on drug release from controlled drug delivery systems. Acta Pol Pharm. 2010; 67 (3): 217-223. 